\title{
Regenerative Endodontic Procedures in Immature Permanent Teeth With Dental Trauma: Current Approaches and Challenges
}

\author{
Caixia Zhou ${ }^{1,2,3 \dagger}$, Zhenglin Yuan ${ }^{1,2,3 \dagger}$, Hanxin $X u^{1,2,3}$, Linrui $W u^{1,2,3}$, Chun $X i^{1,2,3 *}$ and \\ Jiarong Liu ${ }^{1,2,3 *}$ \\ ${ }^{1}$ Department of Stomatology, Union Hospital, Tongji Medical College, Huazhong University of Science and Technology, \\ Wuhan, China, ${ }^{2}$ School of Stomatology, Tongji Medical College, Hulazhong University of Science and Technology, \\ Wuhan, China, ${ }^{3}$ Hubei Province Key Laboratory of Oral and Maxillofacial Development and Regeneration, Wuhan, China
}

After dental trauma to immature permanent teeth (IPT), there can be pulpitis, necrotic, and periapical periodontitis, which will halt further root development. Traditional endodontic root canal treatments and apexification cannot revitalize the necrotic pulp to revitalize the tooth to promote further root development. As a consequence, IPT with thin dentinal walls can be prone to fracture and if a fracture occurs, the patient will likely suffer the loss of the tooth. In an attempt to save IPT, there has been a growing interest among dentists to use regenerative endodontic procedures (REPS) to revitalize a replace dental pulp to continue root development and strengthen the dentinal walls to help prevent a subsequent loss of the tooth. However, the effectiveness of REPs and the precise methods to successfully accomplish REPs are controversial. Therefore, the objective of this review is to compare the different approaches to REPs in case reports by highlighting their advantages and limitations.

Keywords: dental trauma, dental pulp injury, immature permanent tooth, regenerative endodontic procedures, partial pulpotomy, pulp regeneration

\section{INTRODUCTION}

Dental trauma can affect $7.4-58 \%$ of children aged $8-11$ years old (1-3). Dental trauma usually causes injuries to the enamel, dentin, pulp, periodontium, gingiva, and supporting bone structures (4). Dental trauma can create many complications such as pulpitis, pulp necrosis, periapical periodontitis, root hypoplasia, root/alveolar bone resorption, tooth fracture, and shedding of a permanent tooth $(5,6)$. Due to the fact that the root development of immature permanent teeth (IPT) is not complete, these teeth can be fragile and prone to fracture. This is because the dentinal walls can be very thin and if the tooth becomes fractured, it may not be restorable and the whole tooth is lost. IPT are especially prone to fracture because the enamel and dentinal walls can be very thin and weak (7). In addition, the dentine is weaker because the diameter of dentin tubules is large and the peritubule dentin and intertubule dentin are less mineralized (8). IPT also have a large vascularized intracanal dental pulp root canal space and open apical foramen. On the one hand, if an IPT becomes infected, the pulp has a strong resistance to disease and excellent self-healing capacity; on the other hand, an infection can spread quickly and cause periapical periodontitis and in these cases to alleviate patient suffering, a root canal treatment or apexification should be performed (7). 
Immature permanent teeth do not benefit from a traditional root canal treatment or apexification because although the infected and necrotic pulp tissues can be removed, the remaining dentinal walls are thin, fragile, and weak, making them prone to fracture. Because there is no vital dental pulp, root development has stopped and the dentinal walls will remain thin, fragile, and weak. This explains why there has been an increasing interest in using regenerative endodontic procedures (REPs) to revitalize replacement pulp tissues in IPT following pulp necrosis to attempt to continue root development and to continue dentin deposition along the dentinal walls to make them thicker, stronger, and less prone to fracture.

Regenerative endodontic procedures are defined as "biologically-based procedures aimed to replace damaged structures, including dentin and root structures, as well as cells of the pulp-dentin complex" (9). The history of REPs can be traced back to 1952 when Dr. Hermann published a case report of a vital-amputated dental pulp capped with Calxyl (10). Dr. Herman was a pioneer in preserving the pulp tissue following amputation. During the past 70 years, due to advances in biocompatible biomaterials such as the widespread use of mineral trioxide aggregate (MTA) to preserve the vitality of pulp tissues, together with better root canal instruments for debridement and instrumentation and the use of improved radiographic root canal visualization technologies to more accurately noninvasively assess the healing of regenerated tissues, REPs have gradually evolved to incorporate elements of other endodontic treatments. Or, in some places to replace them, such as direct pulp capping, partial pulpotomy, apexification, apexogenesis, and pulp revascularization, to be used for IPT to continue root development, as an alternative to apexification $(11,12)$.

Several clinical and preclinical studies have shown that it may be possible to limit the pulp necrosis from trauma by amputating the non-vital pulp and leaving the remaining vital pulp to heal, by removing the necrotic pulp and revascularizing the root canal space to create replacement pulp tissue, or by using tissue-engineered scaffolds and stem cells to regenerate a dental pulp within the root canal space. In addition to showing new pulp tissue regeneration, it may also be possible for periapical lesions to heal and to continue root development to strengthen the dentinal root canal walls (13-17). However, there can be substantial variations between the current REPs guidelines and the actual clinical procedures used by different dentists $(18,19)$. Most case reports show that REPs have favorable clinical outcomes, but the amount of favorable outcomes for different REPs has proved to be controversial (12, 20, 21). Therefore, the objective of this review is to compare the different approaches to REPs in case reports by highlighting their advantages and limitations.

\section{CURRENT APPROACHES FOR REPS}

The selection of a REP for an IPT with a traumatized dental pulp can vary according to the size and duration of the pulp exposure. According to the traditional view, if the diameter of the exposed pulp after trauma was $<1 \mathrm{~mm}$, direct pulp capping could be applied within 2-3 h (22).

Pulp capping is the simplest approach to treating an exposed dental pulp in a fractured IPT. However, due to the problem of its poor prognosis due to infection and necrotic tissue damage spreading to the remainder of the pulp, it has been suggested that the portion of the damaged pulp should be amputated and partial pulpotomy can be performed. This is because the prognosis of a partial pulpotomy is greater than direct pulp capping $(23,24)$. It was suggested that a delayed partial pulpotomy treatment given within 9 days after trauma could be successful if the diameter of pulp exposure was $<4 \mathrm{~mm}$ (13).

Apexification or calcium hydroxide $\left[\mathrm{Ca}(\mathrm{OH})_{2}\right]$ obturation treatment of the apical foramen to induce calcification is a traditional treatment for a fractured IPT. However, apexification can only induce limited mineralization; it may not be able to prevent a subsequent root canal fracture of fragile IPT with thin dentinal walls (25). This is because apexification cannot promote the formation of functional pulp-dentin complex and root development $(26,27)$.

Several clinical studies have reported the success of REPs in IPT such as apical healing, mineralized tissue apposition, and continued root development of varying degrees $(14,17)$.

Regenerative endodontic procedures involving the implantation of dental pulp stem cells (DPSCs) seeded on collagen scaffolds combined with a growth factor called granulocyte colony-stimulating factor (G-CSF) can induce the complete regeneration of a replacement functional dental pulp, which can mineralize dentin (15). An electric pulp test of the regenerated pulp at 4 weeks posttransplantation displayed a robust positive response. After 24 weeks, the regenerated dental pulp had a similar MRI appearance to a normal dental pulp.

A phase I clinical trial of REPs involving the implantation of DPSCs from human exfoliated deciduous teeth (SHED) revealed the excellent potential of SHED to regenerate a dental pulp, which contained an odontoblast-like layer, blood vessels, and nerves. The sensitivity of the regenerated pulp was able to sense external temperature stimuli (16).

\section{PARTIAL PULPOTOMY OF THE EXPOSED DENTAL PULP}

The aim of a partial pulpotomy is to remove the infected and necrotic pulp under aseptic conditions and to seal the exposed pulp access to prevent the invasion of the bacteria (as shown in Figure 1A) $(28,29)$. Partial pulpotomy can help to preserve the coronal pulp and promote the deposition of cervical dentin; it is also beneficial for maintaining the natural color and translucency of the teeth (13).

The first step for a successful partial pulpotomy requires that hemostasis; the bleeding from the exposed dental pulp be stopped, prior to sealing the exposed pulp. Physiologic saline, 3\% $\mathrm{NaOCl}$, and $2 \%$ chlorhexidine are often used as three of the most safe and cost-effective hemostatic agents. These are applied on a sterile cotton pellet, which is placed onto the exposed dental pulp wound for 5-10 min (30). After the bleeding has stopped, 


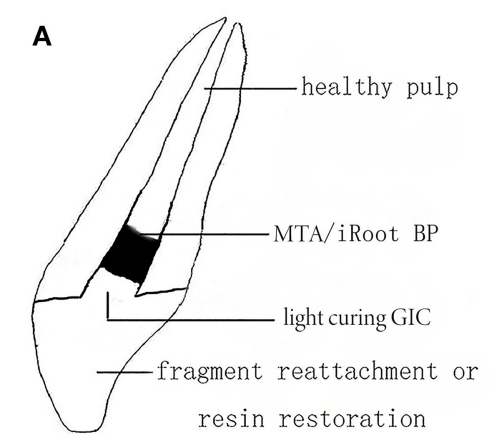

1. Remove infected pulp tissue.

2. Place a small cotton with $3 \% \mathrm{NaOCl} / \mathrm{Saline}$ on the pulp wound as a hemostatic agents for 5-10min.

3. Place MTA/iRoot BP close to but no stress on the pulp.

4. Fragment reattachment or esthetic resin restoration.

\title{
Procedures of partial pulpotomy
}

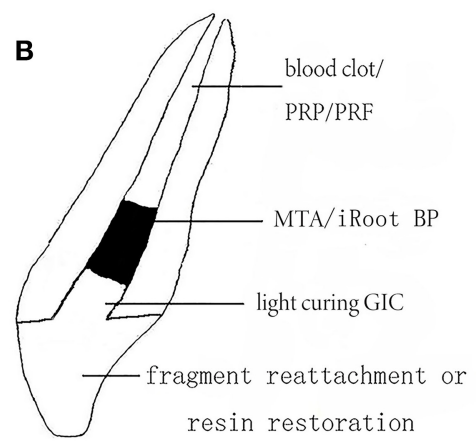

\author{
1. Gently irrigate with a combination of $1.5 \sim 3 \% \mathrm{NaOCl}$ \\ and $17 \%$ EDTA,then rinse with saline. \\ 2. Place $\mathrm{Ca}(\mathrm{oH}) 2$ in the canal for 1-4 weeks. \\ 3. Create bleeding or import PRP/PRF into the canal \\ by instrument. \\ 4. Place MTA/iRoot BP as the capping material. \\ 5. Fragment reattachment or esthetic resin resto- \\ ration.
}

\section{Procedures of pulp revascularization}

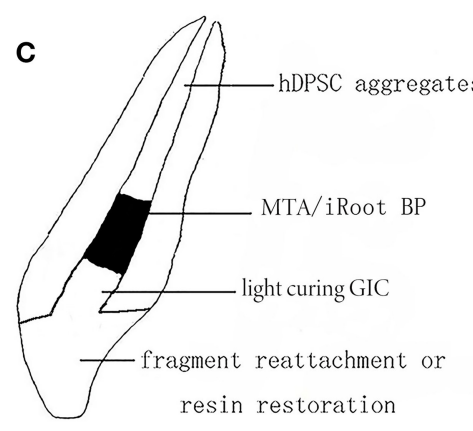

1. Gently irrigate with a combination of $1.5 \sim 3 \% \mathrm{NaOCl}$ and $17 \%$ EDTA, then rinse with saline.

2. Place $\mathrm{Ca}(\mathrm{oH}) 2$ in the canal for 1-4 weeks.

3. Implant stem cells with or without scaffold and bioactive signaling molecules into the canal.

4. Place MTA/iRoot BP as the capping material. 5. Fragment reattachment or esthetic resin restoration.

\section{Procedures of pulp regeneration with cells}

FIGURE 1 | (A-C) Patterns of three regenerative endodontic procedures (REPs) in immature permanent teeth (IPT).

the pulp may be considered to have enough vitality to perform a partial pulpotomy procedure. If the bleeding is not stopped, it may be necessary to consider pulpotomy or even pulpectomy because an exposed pulp, which continues bleeding, has a poor partial pulpotomy prognosis (11).

After hemostasis is accomplished, a dry sterile cotton pellet is used to dry the moisture from the surface of the exposed dental pulp to create a good substrate for the bonding of the restorative dental material. A liner of MTA or another biocompatible biomaterial should be placed in direct contact with the exposed vital dental pulp (13). The pulp capping biomaterial should be biocompatible, be able to seal the pulp access to prevent microleakage, maintain pulp vitality, and induce the formation of a dentin bridge $(31,32)$. A regenerated dental-like structure that resembled secondary dentin was formed and the thickness of such reparative tissue was increased when recombinant human platelet-derived growth factor (PDGF) + MTA was used (33).

Calcium hydroxide has a long history of use as a pulpcapping agent for IPT and it may still have some advantages. However, after the advent of MTA in its various forms [iRoot 
BP, Biodentine, Portland cement (PC), and calcium-enriched mixture], it has become the most widely used pulp capping biomaterial $(18,19,24,34,35)$. Most of these MTA pulp capping materials displayed similar clinical success rates when used in a partial pulpotomy, but iRoot BP was more convenient to handle because it was premixed (36). The restorative dental material can be a composite resin or a temporary glass ionomer cement because of its ease of bonding to the tooth substrate (37). Three cases of partial pulpotomy with different pulp capping biomaterials are shown in Figure 2.

\section{REGENERATIVE ENDODONTIC PROCEDURES WITHOUT THE APPLICATION OF EXOGENOUS CELLS}

Revascularization or the creation of a blood clot within the root canal is the most widely used REP because it does not require the implantation of scaffolds or exogenous stem cells (Figure 1B). The success rate of revascularization treatment can depend on three elements: the effectiveness of root canal disinfection $(20,38,39)$, the ability to create a blood clot that completely fills the root canal space (21), and the use of a biomaterial which seals effectively to prevent microleakage filling $(28,29)$. Revascularization REPs requires insertion of medicine into the root canal and irrigation to remove the necrotic pulp and to disinfect the root canals and probe the periapical tissues through the apical foramen to accomplish bleeding to fill the empty root canal space $(11,12)$.

Regenerative endodontic procedure root canal disinfection can be performed by irrigation followed by the insertion of antimicrobial medicaments into the root canal space for a month. The combined use of a 17\% EDTA chelating agent and a 1.5$3 \% \mathrm{NaOCl}$ disinfectant for irrigation can create a root canal environment beneficial for a replacement pulp regeneration (40). Due to the disinfection of the root canal space, it allows stem cells originating from the apical papilla to survive and differentiate due to the low toxicity environment $(41,42)$. Alternatively, a $2 \%$ chlorhexidine solution can be used as a broad-spectrum antibacterial irrigation agent. It has the advantage of being relatively less toxic than $\mathrm{NaOCl}$. It also has longer substantivity because the positive charge of chlorhexidine molecule combines with the negative charge of the tooth surface, resulting in long-term adhesion and, thus, long-term antibacterial activity. However, a disadvantage of chlorhexidine is that it lacks a tissuedissolution ability (43).

A combination of $2 \%$ chlorhexidine and $\mathrm{NaOCl}$ could disinfect Enterococcus faecalis (44). However, the combined mixture is prone to form precipitates, which could clog dentin tubules and prevent sealing and the adhesion of the restorative material (43). After irrigation with disinfectant solutions or chelating agents, it is recommended to flush the root canal space with saline, to help remove any residual precipitates, necrotic pulp, and debris (45).

Root canal disinfection for REPs can be accomplished with the temporary placement of a combination of antibiotics (46, 47). However, this may create the risk of developing bacterial

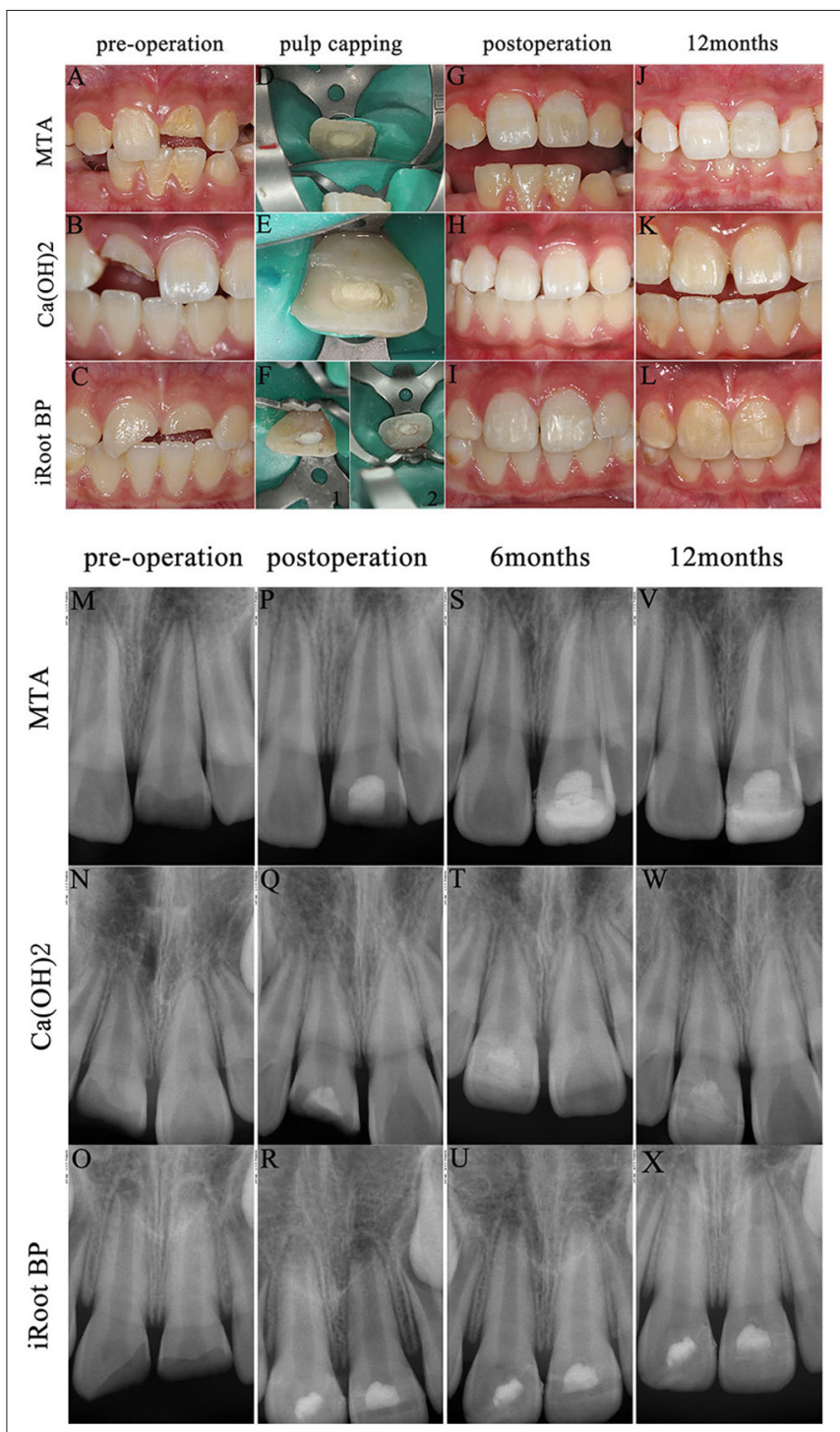

FIGURE 2 | Cases of partial pulpotomy with three pulp-capping agents. (1) Preoperative intraoral photograph $(\mathbf{A}-\mathbf{C})$ and radiographs for each specimen (M-O). Pulp capping process [D: mineral trioxide aggregate (MTA) (Dentsply Sirona, North Carolina, USA); E: Dycal (Dentsply Sirona, North Carolina, USA); F: iRoot BP Plus (Innovative BioCeramix Incorporation, Vancouver, Canada)]. Intraoral photograph after composite resin restoration 3 weeks after pulp capping process (G-I). Radiographs (P-R) immediately after pulp capping operation. Radiographs of 6 months follow-up in all three cases (S-U). Intraoral photographs ( $\mathbf{J}-\mathbf{L})$ and radiographs $(\mathbf{V}-\mathbf{X})$ at postoperative 12 months. (2) No pain, gingival fistula, and other discomfort symptoms occurred and radiographs displayed the length of root, the thickness of canal, and the size of apical foramen distinctively developed. (3) iRoot BP performed advantages of easyhandling and enough time to pulp capping. Both the cases covered with Dycal and iRoot BP did not show discoloration, while the case with MTA turned gray. The composite resin fell off because of biting in the case with MTA pulp capping at postoperative 12 months. Then, we performed secondary resin restoration, which partly covers the discoloration.

endodontic infections with drug resistance to the antibiotics and also allergic reactions to the antibiotics (48). The most widely used disinfectant for REPs is Hoshino's broad-spectrum triple 
antibiotic paste. The paste includes minocycline, which could cause significant staining of the IPT $(49,50)$. The European Society of Endodontology advocated the use of $\mathrm{Ca}(\mathrm{OH})_{2}$ as a root canal disinfectant for REPs over Hoshino's triple antibiotic paste because $\mathrm{Ca}(\mathrm{OH})_{2}$ can release transforming growth factor$\beta 1$ (TGF- $\beta 1$ ) from dentin (51). $\mathrm{Ca}(\mathrm{OH})_{2}$ can be used to disinfect root canals and has the advantage of promoting higher concentrations of apical stem cells survival (52).

After root canal disinfection, revascularization using a blood clot must be created that fills the root canal space with a blood clot scaffold for pulp regeneration. The bleeding into the root canal space is induced by placing a k-file through the open apical foramen, up to 2-4 mm into the periapical tissues (12). The blood clot scaffold can be augmented to use platelet-rich plasma (PRP) or platelet-rich fibrin (PRF) to promote the faster regeneration of a replacement dental pulp $(53,54)$. After the root canal space is filled with a blood clot, a 3-4 mm layer of MTA or some other kind of biocompatible bioceramic should be placed over the blood clot as a capping material $(17,55)$. The American Association of Endodontists suggests placing a temporary lightcured glass ionomer cement over the surface of the MTA to prevent microleakage or to restore the root canal access and seal the MTA permanently with a complete resin filling. Two REP cases are shown in Figure 3.

\section{REGENERATIVE ENDODONTIC PROCEDURES WITH IMPLANTED STEM CELLS}

The effectiveness of the REPs to regenerate a replacement dental pulp may be increased by augmenting the blood clot revascularization approach with implanted stem cells (Figure 1C). The blood clot revascularization is necessary to supply the implanted stem cells with oxygen and nutrients for survival. Generally, the REP that implants stem cells also requires a scaffold to support the structure of a replacement dental pulp and also growth factors and/or signaling biomolecules to promote stem cell differentiation into tissues (56).

The most common types of implanted stem cells for REPs are SHED and stem cells originating from pulp (DPSC) and apical papilla $(\mathrm{SCAP})(15,16,57)$. In addition, periodontal ligament stem cells (PDLSCs), bone marrow stem cells (BMSCs), and allogenic umbilical cord mesenchymal stem cells (UC-MSCs) can generate similar tissues within the revascularized root canal space $(58,59)$. The stem cells have been combined with two types of scaffolds: natural scaffolds such as PRP, PRF, and platelet-poor plasma (PPP) (59-61) and synthetic scaffolds such as poly-Llactic acid (PLLA) (62).

The most common biomolecules for promoting stem cell activity as part of REPs are TGF- $\beta$ (63), bone morphogenetic protein (BMP) (64), PDGF (65), vascular endothelial growth factor (VEGF) (64), and G-CSF (15). These biomolecules could be released from demineralized dentin matrix or delivered exogenously to facilitate pulp-dentin regeneration (66).

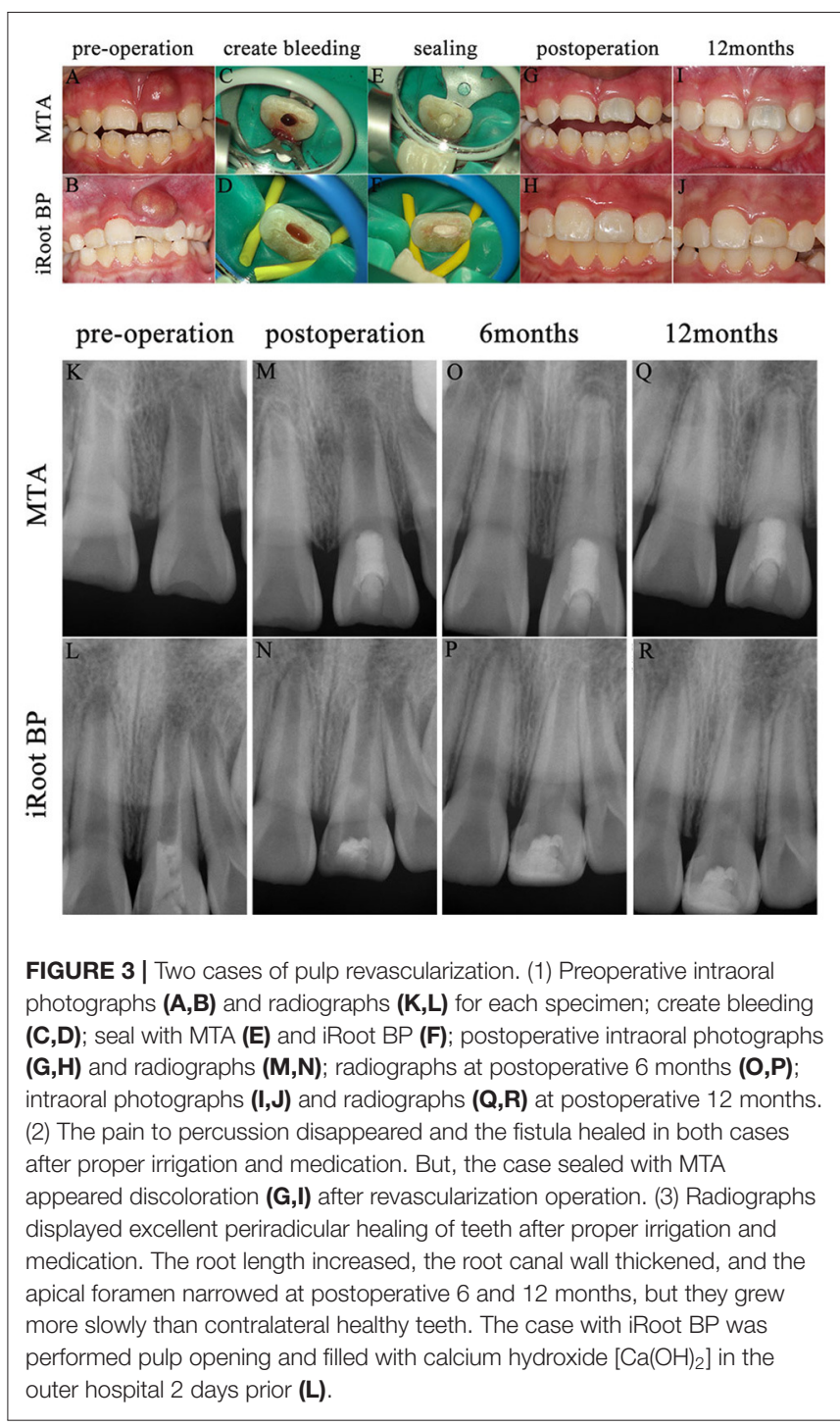

\section{CLINICAL ISSUES AND LIMITATIONS}

It seemed that a standardized clinical approach for pulp injury in IPT was introduced clearly. For example, injured teeth with uninfected pulp should receive the procedure of partial pulpotomy, while injured teeth with infected or necrotic pulp receive pulpectomy (11). However, most dentists inevitably modified their treatment procedures based on their clinical judgment. It was demonstrated that IPT with partial pulp necrosis and symptomatic apical periodontitis could achieve successful outcomes by the partial pulpotomy (18, 19), which could be explained that the pulp of immature permanent teeth had a strong disease resistance and repair function due to its unique physiological and anatomical characteristics (7). In addition, it was also explained that the clinical diagnosis of pulp status was inaccurate, especially for traumatic teeth (67). Furthermore, the preoperative pulp status was merely identified as the significant factor by 
examining probable partial pulpotomy prognostic factors using meta-regression analysis (24).

Sensitivity or sensibility (thermal and electrical) tests are commonly used by dentists to determine the vitality status of the dental pulp. However, the accuracy of the tests can be disturbed by the subjectivity of the patient's response, which may be related to the perception of the pain threshold, the changes in the supporting dental tissues, and transient paresthesia in newly traumatized teeth (67). The use of laser/ultrasound Doppler flowmetry appeared to be more sensitive in assessing the pulp vitality in traumatized teeth, compared to cold and heat. But, the extent of dental pulp necrosis can only be definitively confirmed by a histological assessment $(67,68)$. The judgment of the realtime pulp state mainly depended on the intraoperative evaluation of pulp exposure range, blood loss, duration, hemostasis ability, and exudate at the injury site $(11,24,31)$. Thus, accurate assessment of pulp status is conducive to the selection of more appropriate therapeutic modalities.

All the REPs involve revascularization of tissues within the root canal to replace the functions of the necrotic pulp such as to continue root maturation, enhance apical healing, and most importantly to mineralize the dentinal walls to thicken them and strengthen the tooth against fracture $(14,17)$. Histological observations of the de novo revascularized replacement pulp tissue have revealed that it can have a different pathology and be more heterogeneous to the original dental pulp tissues that formed in the root canal during tooth development. The replacement revascularized tissues appeared to most commonly have a more similar pathology to periodontal tissues such as cementum, periodontal ligament, and bone (69-72). However, the de novo dental pulp revascularized tissues commonly contain blood vessels and blood cells, lymphatic cells, mineralized dentinlike structures, and immune cells expressing inflammatory markers (73). The histological and pathological observations of the de novo dental pulp revascularized tissues suggest that it includes stem cells sourced from residual vital stem cells in the apical third of the root canal (16). Stem cells may home by migration toward growth factors released within the disinfected root canal space, from the apical papilla, periodontal ligament, and from bone (69). Nevertheless, the major limiting factor, in being able to regenerate a whole de novo replacement pulp tissue, is likely the small numbers of available stem cells and also their ability to migrate into root canals, adhere to the root canal walls, and obtain oxygen and nutrients to form replacement dental pulp-like tissues $(16,59,69)$. Not all the REPs are successful, some studies have reported failures of revascularization to heal periapical lesions or even for periapical lesions to recur. REPs can also fail to continue root formation and the tooth does not mature. REPs can also cause a partial or complete intracanal obliteration $(12,20,21)$.

Vital dental pulp tissue in IPT must be protected from trauma and microleakage to avoid necrosis. The dental pulp has a limited capacity to heal and form tertiary dentin bridges in response to wear, erosion, and fractures or restorations that are very close to the pulp. Human teeth do not have a good self-healing capacity when compared with rodents and other animals; hence, care is needed when extrapolating animal studies to the clinical outcome because dental treatments which are successful in animals are not commonly successful in humans.

The use of root canal debridement to effectively remove necrotic dental pulp and the effective disinfection of the root canal space must be accomplished to ensure the success of REPs to revascularize or bioengineer replacement dental pulp (74). DPSCs are not resistant to severe inflammation and are not suitable for dental pulp regeneration in an inflammatory environment, but they may survive where there is reversible inflammation (75). Due to the modern concept of minimally invasive dentistry, the most minimalist treatments are preferred. The use of bioengineering and harvesting dental stem cells such as autologous DPSCs/SHED for dental pulp tissue regeneration is not minimalist. Thus, the minimalist era of dentistry may be passing and we should now embrace the era of regeneration because of the various dental stem cell therapies under development $(15,16)$. Based on the increasing popularity of dental stem cell banking, we can expect new applications for dental stem cells that have been harvested from baby teeth, which may be for autologous tissue regeneration for all replacement body tissues, not only for the dental pulp.

The application of bioengineered REPs with stem cells, growth factors, and scaffolds to accomplish regeneration could help to promote the formation of replacement dental pulps that have histology and pathology which more closely resembles the original dental pulp tissue, such as having an odontoblast-like layer of cells to remineralize the dentinal walls and to form connective tissue, blood vessels, and nerves $(15,16)$. However, there are valid concerns about the long-term efficacy and safety of transplanting bioengineered tissues containing stem cells into patients. All stem cell therapies are risky because the cells may malfunction and risk causing cancer or form abnormal tissues elsewhere in the body; the cells may also be attacked by the host immune system. Prior to clinical, there are many problems to overcome such as the problems of harvesting and isolating pure cultures of autologous stem cells from patients, stem cell storage in serum-free media, limitations of cell culture expansion, the growth and handling of cells without contamination, the lack of good manufacturing practice facilities, government regulatory policies which prevent stem cell transplantation, and the lack of training by clinicians to perform REPs, with or without bioengineered tissues (76). It is clear that new imaging and safer bioengineering technologies will keep improving the ability of clinicians to regenerate replacement tissues for patients because there is a demand for regenerated dental pulp, replacement teeth, and other dental tissues that are malformed, diseased, or missing. Further investments in research are needed to bring all the regenerative technologies to fruition for dentists to alleviate the suffering of dental patients.

\section{FUTURE AND CONCLUSION}

Following dental trauma, the dentist must accurately diagnose the vitality status of the injured dental pulp and decide if there is reversible pulpitis, which will not become necrosis, irreversible pulpitis which will become necrosis, or if there is 
already necrosis, or if all the tissues are vital and not likely to become necrotic. The accurate diagnosis of pulp necrosis and pulpitis is the key step in deciding which treatment to provide. As a general rule, necrotic tissues and dental pulps with irreversible pulpitis will become necrotic. Necrotic dental pulps cannot be saved and must always be amputated, pulptomized, debrided, or removed completely, and the surrounding vital or mineralized tissues must be disinfected to create a root canal system that is suitable for revascularization and the de novo dental pulp tissue regeneration or apexification if using REP is not possible. If the dental pulp is vital and does not have irreversible pulpitis, with little risk of infection due to very minor trauma, it may be possible to preserve the dental pulp using a pulp capping or partial pulpotomy procedure. However, only a few dentists possess adequate training and experience to deliver partial pulpotomy or revascularization and almost no dentists have suitable skills or technology to deliver bioengineered tissues to their patients. Dental biomaterial suppliers also need to develop dental tissue regeneration kits with instructions on delivering safe and effective advanced technology treatments.

\section{REFERENCES}

1. Hamilton FA, Hill FJ, Holloway PJ. An investigation of dento-alveolar trauma and its treatment in an adolescent population. Part. 1: the prevalence and incidence of injuries and the extent and adequacy of treatment received. $\mathrm{Br}$ Dent J. (1997) 182:91-95. doi: 10.1038/sj.bdj.4809313

2. Glendor U. Epidemiology of traumatic dental injuries-a 12 year review of the literature. Dent Traumatol. (2008) 24:603-11. doi: $10.1111 / j .1600-9657.2008 .00696 . x$

3. Diangelis AJ, Andreasen JO, Ebeleseder KA, Kenny DJ, Trope M, Sigurdsson A, et al. International Association of Dental Traumatology guidelines for the management of traumatic dental injuries: 1. Fractures and luxations of permanent teeth. Dent Traumatol. (2012) 28:2-12. doi: 10.1111/j.1600-9657.2011.01103.x

4. Andreasen JQ, Andreasen L. Textbook and Color Atlas of Traumatic Injuries to the Teeth. Copenhagen: Blackwell Munksgaard (2007).

5. Andreasen FM, Kahler B. Pulpal response after acute dental injury in the permanent dentition: clinical implications-a review. J Endod. (2015) 41:299308. doi: 10.1016/j.joen.2014.11.015

6. Korolenkova MV, Rakhmanova MS. [Outcomes of traumatic dental injuries in children]. Stomatologiia. (2019) 98:116-22. doi: 10.17116/stomat201998041116

7. Nanci A. Ten Cate's Oral Histology: Development, Structure, and Function. St. Louis, MO: Elsevier Press (2018).

8. Kinney JH, Nalla RK, Pople JA, Breunig TM, Ritchie RO. Agerelated transparent root dentin: mineral concentration, crystallite size, mechanical properties. Biomaterials. (2005) 26:3363-76. doi: 10.1016/j.biomaterials.2004.09.004

9. Murray PE, Garcia-Godoy F, Hargreaves KM. Regenerative endodontics: a review of current status and a call for action. J Endod. (2007) 33:377-90. doi: 10.1016/j.joen.2006.09.013

10. Hermann BW. [On the reaction of the dental pulp to vital amputation and calxyl capping]. Dtsch Zahnarztl Z. (1952) 7:1446-7.

11. Garcia-Godoy F, Murray PE. Recommendations for using regenerative endodontic procedures in permanent immature traumatized teeth. Dent Traumatol. (2012) 28:33-41. doi: 10.1111/j.1600-9657.2011.01044.x

12. Jung C, Kim S, Sun T, Cho YB, Song M. Pulp-dentin regeneration: current approaches and challenges. J Tissue Eng. (2019) 10:1544418625. doi: $10.1177 / 2041731418819263$

13. Bimstein E, Rotstein I. Cvek pulpotomy - revisited. Dent Traumatol. (2016) 32:438-42. doi: 10.1111/edt.12297
The future direction of dentistry is clear and it is inevitable that future dentists will be bioengineers who can create all types of replacement tissues for their patients.

\section{AUTHOR CONTRIBUTIONS}

CZ gathered information, drafted the manuscript, and provided two cases. ZY was responsible for revising the manuscript and providing fund support. HX provided two cases. LW provided one case. CX and JL designed the ideas, revised the manuscript, and the latter provided funding. All authors contributed to the article and approved the submitted version.

\section{FUNDING}

This work was supported by the Science Foundation of Hubei Provincial Health Committee (No. WJ2019M157) and the Project from the National Natural Science Foundation of China (No. 81700955).

14. He L, Zhong J, Gong Q, Kim SG, Zeichner SJ, Xiang L. Treatment of necrotic teeth by apical revascularization: meta-analysis. Sci Rep. (2017) 7:13941. doi: $10.1038 / \mathrm{s} 41598-017-14412-\mathrm{x}$

15. Nakashima M, Iohara K, Murakami M, Nakamura H, Sato Y, Ariji Y. Pulp regeneration by transplantation of dental pulp stem cells in pulpitis: a pilot clinical study. Stem Cell Res Ther. (2017) 8:61. doi: 10.1186/s13287-017-0506-5

16. Xuan K, Li B, Guo H, Sun W, Kou X, He X. Deciduous autologous tooth stem cells regenerate dental pulp after implantation into injured teeth. Sci Transl Med. (2018) 10:eaaf3227. doi: 10.1126/scitranslmed.aaf3227

17. Aly MM, Taha S, El SM, Youssef R, Omar HM. Clinical and radiographic evaluation of biodentine and mineral trioxide aggregate in revascularization of non-vital immature permanent anterior teeth (randomized clinical study). Int J Paediatr Dent. (2019) 29:464-73. doi: 10.1111/ipd.12474

18. Jiang $\mathrm{S}, \mathrm{Wu} \mathrm{H}$, Zhang CF. Partial pulpotomy of immature teeth with apical periodontitis using bioceramics and mineral trioxide aggregate: a report of three cases. Chin J Dent Res. (2016) 19:115-20. doi: 10.3290/j.cjdr.a36182

19. Chinadet W, Sutharaphan T, Chompu-Inwai P. Biodentine partial pulpotomy of a young permanent molar with signs and symptoms indicative of irreversible pulpitis and periapical lesion: a case report of a five-year follow-up. Case Rep Dent. (2019) 2019:8153250. doi: 10.1155/2019/8153250

20. Lin LM, Shimizu E, Gibbs JL, Loghin S, Ricucci D. Histologic and histobacteriologic observations of failed revascularization/revitalization therapy: a case report. J Endod. (2014) 40:291-5. doi: 10.1016/j.joen.2013.08.024

21. Song M, Cao Y, Shin SJ, Shon WJ, Chugal N, Kim RH, et al. Revascularizationassociated intracanal calcification: assessment of prevalence and contributing factors. J Endod. (2017) 43:2025-33. doi: 10.1016/j.joen.2017.06.018

22. Andreasen JO, Andreasen FM, Skeie A, Hjorting-Hansen E, Schwartz O. Effect of treatment delay upon pulp and periodontal healing of traumatic dental injuries - a review article. Dent Traumatol. (2002) 18:116-28. doi: 10.1034/j.1600-9657.2002.00079.x

23. Aguilar P, Linsuwanont P. Vital pulp therapy in vital permanent teeth with cariously exposed pulp: a systematic review. J Endod. (2011) 37:581-7. doi: 10.1016/j.joen.2010.12.004

24. Elmsmari F, Ruiz XF, Miro Q, Feijoo-Pato N, Duran-Sindreu F, Olivieri JG. Outcome of partial pulpotomy in cariously exposed posterior permanent teeth: a systematic review and meta-analysis. J Endod. (2019) 45:1296-306. doi: 10.1016/j.joen.2019.07.005

25. Chen SJ, Chen LP. Radiographic outcome of necrotic immature teeth treated with two endodontic techniques: a retrospective analysis. Biomed J. (2016) 39:366-71. doi: 10.1016/j.bj.2015.12.006 
26. Jeeruphan T, Jantarat J, Yanpiset K, Suwannapan L, Khewsawai P, Hargreaves KM. Mahidol study 1: comparison of radiographic and survival outcomes of immature teeth treated with either regenerative endodontic or apexification methods: a retrospective study. J Endod. (2012) 38:1330-6. doi: 10.1016/j.joen.2012.06.028

27. Sharma S, Sharma V, Passi D, Srivastava D, Grover S, Dutta SR. Large periapical or cystic lesions in association with roots having open apices managed nonsurgically using 1-step apexification based on platelet-rich fibrin matrix and biodentine apical barrier: a case series. J Endod. (2018) 44:179-85. doi: 10.1016/j.joen.2017.08.036

28. Kuo HY, Lin JR, Huang WH, Chiang ML. Clinical outcomes for primary molars treated by different types of pulpotomy: a retrospective cohort study. $J$ Formos Med Assoc. (2018) 117:24-33. doi: 10.1016/j.jfma.2017.02.010

29. Tan SY, Yu V, Lim KC, Tan B, Neo C, Shen L. Long-term pulpal and restorative outcomes of pulpotomy in mature permanent teeth. J Endod. (2020) 46:38390. doi: 10.1016/j.joen.2019.11.009

30. Hemavathi NJ, Srinath SK, Hiremath MC. Clinical and radiographic evaluation of the efficacy of sodium hypochlorite as a haemostatic agent compared with physiologic saline on the success of calcium hydroxide pulpotomies in primary molars: an in vivo study. Eur Arch Paediatr Dent. (2018) 19:423-30. doi: 10.1007/s,40368-018-0377-1

31. Cho SY, Seo DG, Lee SJ, Lee J, Lee SJ, Jung IY. Prognostic factors for clinical outcomes according to time after direct pulp capping. J Endod. (2013) 39:327-31. doi: 10.1016/j.joen.2012.11.034

32. Ricucci D, Grande NM, Plotino G, Tay FR. Histologic response of human pulp and periapical tissues to tricalcium silicate-based materials: a series of successfully treated cases. J Endod. (2020) 46:307-17. doi: 10.1016/j.joen.2019.10.032

33. Al-Hezaimi K, Naghshbandi J, Alhuzaimi R, Alonizan F, AlQwizany I, Rotstein I. Regeneration of secondary dentin using recombinant human platelet-derived growth factor and MTA for pulp capping: a randomized controlled human clinical trial. Int J Periodontics Restorative Dent. (2020) 40:477-85. doi: 10.11607/prd.4766

34. Chen Y, Chen X, Zhang Y, Zhou F, Deng J, Zou J, et al. Materials for pulpotomy in immature permanent teeth: a systematic review and meta-analysis. $B M C$ Oral Health. (2019) 19:227. doi: 10.1186/s12903-019-0917-z

35. Maroto M, Barreiro S, Barberia E. Portland cement as pulp dressing agent in pulpotomy treatment of primary molars: a 12-month clinical study. Eur J Paediatr Dent. (2019) 20:23-6. doi: 10.23804/ejpd.2019.20.01.05

36. Zhou W, Zheng Q, Tan X, Song D, Zhang L, Huang D. Comparison of mineral trioxide aggregate and iRoot BP Plus root repair material as root-end filling materials in endodontic microsurgery: a prospective randomized controlled study. J Endod. (2017) 43:1-6. doi: 10.1016/j.joen.2016.10.010

37. Baroudi K, Rodrigues JC. Flowable resin composites: a systematic review and clinical considerations. J Clin Diagn Res. (2015) 9:E18-24. doi: 10.7860/JCDR/2015/12294.6129

38. Chaniotis A. Treatment options for failing regenerative endodontic procedures: report of 3 cases. J Endod. (2017) 43:1472-8. doi: 10.1016/j.joen.2017.04.015

39. Verma P, Nosrat A, Kim JR, Price JB, Wang P, Bair E. Effect of residual bacteria on the outcome of pulp regeneration in vivo. J Dent Res. (2017) 96:100-6. doi: $10.1177 / 0022034516671499$

40. Galler KM, Krastl G, Simon S, Van Gorp G, Meschi N, Vahedi B. European Society of Endodontology position statement: revitalization procedures. Int Endod J. (2016) 49:717-23. doi: 10.1111/iej.12629

41. Martin DE, De Almeida JF, Henry MA, Khaing ZZ, Schmidt CE, Teixeira $\mathrm{FB}$, et al. Concentration-dependent effect of sodium hypochlorite on stem cells of apical papilla survival and differentiation. J Endod. (2014) 40:51-5. doi: 10.1016/j.joen.2013.07.026

42. Kharchi AS, Tagiyeva-Milne N, Kanagasingam S. Regenerative endodontic procedures, disinfectants and outcomes: a systematic review. Prim Dent J. (2020) 9:65-84. doi: 10.1177/2050168420963302

43. Ruksakiet K, Hanak L, Farkas N, Hegyi P, Sadaeng W, Czumbel LM. Antimicrobial efficacy of chlorhexidine and sodium hypochlorite in root canal disinfection: a systematic review and meta-analysis of randomized controlled trials. J Endod. (2020) 46:1032-41. doi: 10.1016/j.joen.2020.05.002

44. Mohammadi Z. Sodium hypochlorite in endodontics: an update review. Int Dent J. (2008) 58:329-41. doi: 10.1111/j.1875-595X.2008.tb00354.x
45. Trevino EG, Patwardhan AN, Henry MA, Perry G, Dybdal-Hargreaves N, Hargreaves KM. Effect of irrigants on the survival of human stem cells of the apical papilla in a platelet-rich plasma scaffold in human root tips. J Endod. (2011) 37:1109-15. doi: 10.1016/j.joen.2011.05.013

46. Montero-Miralles P, Martin-Gonzalez J, Alonso-Ezpeleta O, Jimenez-Sanchez MC, Velasco-Ortega E, Segura-Egea JJ. Effectiveness and clinical implications of the use of topical antibiotics in regenerative endodontic procedures: a review. Int Endod J. (2018) 51:981-8. doi: 10.1111/iej.12913

47. Do CA, Espaladori MC, Leite A, Martins CC, de Aguiar M, Abreu LG. A systematic review of pulp revascularization using a triple antibiotic paste. Pediatr Dent. (2019) 41:341-53. Available online at: https://www.aapd.org/ globalassets/media/publications/open-access/341-53.pdf

48. Kaufman AY, Solomonov M, Galieva D, Abbott PV. Allergic reaction to the tetracycline component of ledermix paste: a case report. Int Endod J. (2014) 47:1090-7. doi: 10.1111/iej.12252

49. Althumairy RI, Teixeira FB, Diogenes A. Effect of dentin conditioning with intracanal medicaments on survival of stem cells of apical papilla. J Endod. (2014) 40:521-5. doi: 10.1016/j.joen.2013.11.008

50. Latham J, Fong H, Jewett A, Johnson JD, Paranjpe A. Disinfection efficacy of current regenerative endodontic protocols in simulated necrotic immature permanent teeth. J Endod. (2016) 42:1218-25. doi: 10.1016/j.joen.2016.05.004

51. Galler KM, Buchalla W, Hiller KA, Federlin M, Eidt A, Schiefersteiner M, et al. Influence of root canal disinfectants on growth factor release from dentin. $J$ Endod. (2015) 41:363-8. doi: 10.1016/j.joen.2014.11.021

52. Ruparel NB, Teixeira FB, Ferraz CC, Diogenes A. Direct effect of intracanal medicaments on survival of stem cells of the apical papilla. J Endod. (2012) 38:1372-5. doi: 10.1016/j.joen.2012.06.018

53. Murray PE. Platelet-rich plasma and platelet-rich fibrin can induce apical closure more frequently than blood-clot revascularization for the regeneration of immature permanent teeth: a meta-analysis of clinical efficacy. Front. Bioeng. Biotechnol. (2018) 6:139. doi: 10.3389/fbioe.2018. 00139

54. ElSheshtawy AS, Nazzal H, El SO, El BA, Ismail SM, Kang J, et al. The effect of platelet-rich plasma as a scaffold in regeneration/revitalization endodontics of immature permanent teeth assessed using 2-dimensional radiographs and cone beam computed tomography: a randomized controlled trial. Int Endod J. (2020) 53:905-21. doi: 10.1111/iej.13303

55. Liu S, Wang S, Dong Y. Evaluation of a bioceramic as a pulp capping agent in vitro and in vivo. J Endod. (2015) 41:652-7. doi: 10.1016/j.joen.2014. 12.009

56. Orti V, Collart-Dutilleul PY, Piglionico S, Pall O, Cuisinier F, Panayotov I. Pulp regeneration concepts for nonvital teeth: from tissue engineering to clinical approaches. Tissue Eng Part B Rev. (2018) 24:419-42. doi: 10.1089/ten.teb.2018.0073

57. Hu L, Zhao B, Gao Z, Xu J, Fan Z, Zhang C. Regeneration characteristics of different dental derived stem cell sheets. J Oral Rehabil. (2020) 47(Suppl. 1):66-72. doi: 10.1111/joor.12839

58. Seo BM, Miura M, Gronthos S, Bartold PM, Batouli S, Brahim J. Investigation of multipotent postnatal stem cells from human periodontal ligament. Lancet. (2004) 364:149-55. doi: 10.1016/S0140-6736(04)16627-0

59. Brizuela C, Meza G, Urrejola D, Quezada MA, Concha G, Ramírez V, et al. Cell-based regenerative endodontics for treatment of periapical lesions: a randomized, controlled phase I/II clinical trial. J Dent Res. (2020) 99:523-9. doi: $10.1177 / 0022034520913242$

60. Bezgin T, Yilmaz AD, Celik BN, Kolsuz ME, Sonmez H. Efficacy of plateletrich plasma as a scaffold in regenerative endodontic treatment. J Endod. (2015) 41:36-44. doi: 10.1016/j.joen.2014.10.004

61. Shivashankar VY, Johns DA, Maroli RK, Sekar M, Chandrasekaran R, Karthikeyan S, et al. Comparison of the effect of PRP, PRF and induced bleeding in the revascularization of teeth with necrotic pulp and open apex: a triple blind randomized clinical trial. J Clin Diagn Res. (2017) 11:C34-9. doi: 10.7860/JCDR/2017/22352.10056

62. Cordeiro MM, Dong Z, Kaneko T, Zhang Z, Miyazawa M, Shi S. Dental pulp tissue engineering with stem cells from exfoliated deciduous teeth. J Endod. (2008) 34:962-9. doi: 10.1016/j.joen.2008.04.009

63. Cameron R, Claudia E, Ping W, Erin S, Ruparel NB. Effect of a residual biofilm on release of transforming growth factor betal from dentin. J Endod. (2019) 45:1119-25. doi: 10.1016/j.joen.2019.05.004 
64. Aksel H, Huang GT. Combined effects of vascular endothelial growth factor and bone morphogenetic protein 2 on odonto/osteogenic differentiation of human dental pulp stem cells in vitro. J Endod. (2017) 43:930-5. doi: 10.1016/j.joen.2017.01.036

65. Zhang M, Jiang F, Zhang X, Wang S, Jin Y, Zhang W. The effects of platelet-derived growth factor-BB on human dental pulp stem cells mediated dentin-pulp complex regeneration. Stem Cells Transl Med. (2017) 6:2126-34. doi: $10.1002 /$ sctm.17-0033

66. Kim SG. Biological molecules for the regeneration of the pulp-dentin complex. Dent Clin North Am. (2017) 61:127-41. doi: 10.1016/j.cden.2016.08.005

67. Lima TFR, Dos Santos SL, Da Silva Fidalgo TK, Silva EJNL. Vitality tests for pulp diagnosis of traumatized teeth: a systematic review. J Endod. (2019) 45:490-9. doi: 10.1016/j.joen.2019.01.014

68. Ahn S, Kim D, Park S. Efficacy of ultrasound doppler flowmetry in assessing pulp vitality of traumatized teeth: a propensity score matching analysis. $J$ Endod. (2018) 44:379-83. doi: 10.1016/j.joen.2017.10.004

69. Martin G, Ricucci D, Gibbs JL, Lin LM. Histological findings of revascularized/revitalized immature permanent molar with apical periodontitis using platelet-rich plasma. J Endod. (2013) 39:138-44. doi: 10.1016/j.joen.2012.09.015

70. Becerra P, Ricucci D, Loghin S, Gibbs JL, Lin LM. Histologic study of a human immature permanent premolar with chronic apical abscess after revascularization/revitalization. J Endod. (2014) 40:133-9. doi: 10.1016/j.joen.2013.07.017

71. Lei L, Chen Y, Zhou R, Huang X, Cai Z. Histologic and immunohistochemical findings of a human immature permanent tooth with apical periodontitis after regenerative endodontic treatment. J Endod. (2015) 41:1172-9. doi: 10.1016/j.joen.2015.03.012

72. Nosrat A, Kolahdouzan A, Hosseini F, Mehrizi EA, Verma P, Torabinejad M. Histologic outcomes of uninfected human immature teeth treated with regenerative endodontics: 2 case reports. J Endod. (2015) 41:1725-9. doi: 10.1016/j.joen.2015.05.004
73. Austah O, Joon R, Fath WM, Chrepa V, Diogenes A, Ezeldeen M, et al. Comprehensive characterization of 2 immature teeth treated with regenerative endodontic procedures. J Endod. (2018) 44:1802-11. doi: 10.1016/j.joen.2018.09.007

74. Wolters WJ, Duncan HF, Tomson PL, Karim IE, McKenna G, Dorri M. Minimally invasive endodontics: a new diagnostic system for assessing pulpitis and subsequent treatment needs. Int Endod J. (2017) 50:825-9. doi: 10.1111/iej.12793

75. Ma L, Hu J, Cao Y, Xie Y, Wang H, Fan Z, et al. Maintained properties of aged dental pulp stem cells for superior periodontal tissue regeneration. Aging Di. (2019) 10:793. doi: 10.14336/AD.2018.0729

76. Kim SG, Malek M, Sigurdsson A, Lin LM, Kahler B. Regenerative endodontics: a comprehensive review. Int Endod J. (2018) 51:1367-88. doi: 10.1111/iej.12954

Conflict of Interest: The authors declare that the research was conducted in the absence of any commercial or financial relationships that could be construed as a potential conflict of interest.

Publisher's Note: All claims expressed in this article are solely those of the authors and do not necessarily represent those of their affiliated organizations, or those of the publisher, the editors and the reviewers. Any product that may be evaluated in this article, or claim that may be made by its manufacturer, is not guaranteed or endorsed by the publisher.

Copyright (c) 2022 Zhou, Yuan, Xu, Wu, Xie and Liu. This is an open-access article distributed under the terms of the Creative Commons Attribution License (CC BY). The use, distribution or reproduction in other forums is permitted, provided the original author(s) and the copyright owner(s) are credited and that the original publication in this journal is cited, in accordance with accepted academic practice. No use, distribution or reproduction is permitted which does not comply with these terms. 